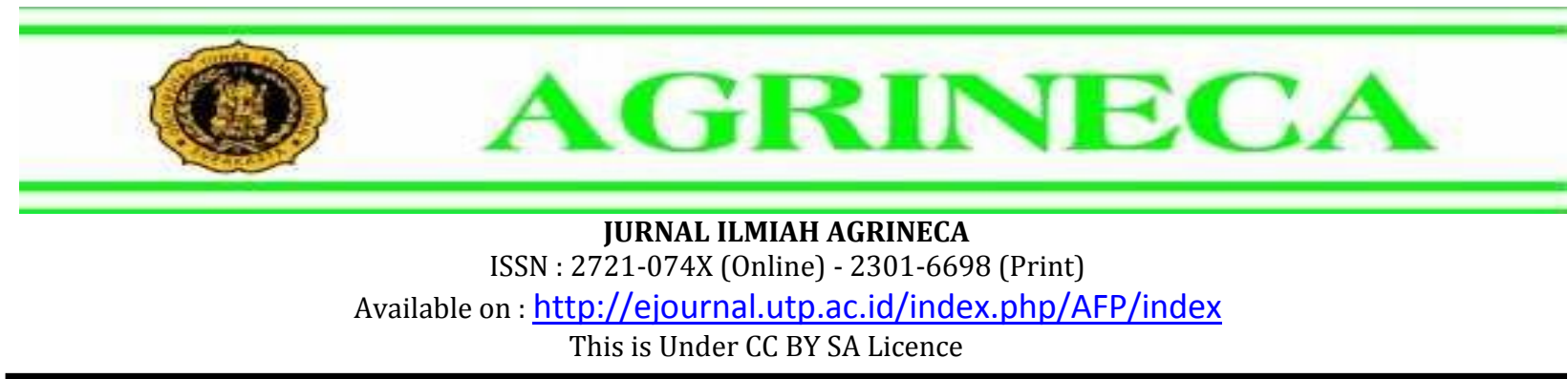

\title{
GOOD AGRICULTURAL PRACTICES BAWANG MERAH (Allium ascalonicum) DENGAN PUPUK KANDANG SAPI, TINJAUAN KEAMANAN PANGAN DARI ASPEK CEMARAN LOGAM BERAT
}

\section{Good Agricultural Practices Shallot (Allium ascalonicum) with Cow Manure, Food Safety Review From Heavy Metal Content Aspects}

\author{
Sapto Priyadi ${ }^{1 *}$, Setie Harieni, Tyas Soemarah KD, Dwi Susilo Utami dan Haryuni \\ ${ }^{1}$ Program Studi Agroteknologi, Fakultas Pertanian, Universitas Tunas Pembangunan, Surakarta \\ Jl. Balekambang Lor No. 1 Manahan Surakarta \\ *Corresponden author:priyadisapto@yahoo.co.id
}

\begin{abstract}
The aim of this research was to determine the effect of manure dosage treatment factors on shallot yield and heavy metal contamination of $\mathrm{Pb}, \mathrm{Cd}$, and $\mathrm{Cu}$. Research factors include the use of cow manure, consisting of 9 levels of doses, namely: 0, 15, 20, 25, 30,35, 40, 45 and $50 \mathrm{~kg} / \mathrm{ha}$. The results showed that the increase in manure dose was followed by an increase in the yield of shallot bulbs. The highest yield of shallot tubers $(3,897.76) \mathrm{kg} / \mathrm{ha}$ was achieved in the treatment of doses of cow manure $50 \mathrm{~kg} / \mathrm{ha}$, the treatment was significantly different from the yield of shallot bulbs $(3,634.73 \mathrm{~kg} / \mathrm{ha}$ at the dose of manure treatment. cattle $45 \mathrm{~kg} / \mathrm{ha}$. While the lowest yield of shallots $(1,875.86) \mathrm{kg} / \mathrm{ha}$ was achieved in the treatment of $0 \mathrm{~kg} / \mathrm{ha}$ without manure. Heavy metal contamination on shallot bulbs in the dose treatment of cow manure $50 \mathrm{~kg} / \mathrm{ha}$ consecutively: Pb (15,350) ppm, Cd (undetectable) detection limit of $0.01 \mathrm{ppm}$, and $\mathrm{Cu}(4,255) \mathrm{ppm}$. Heavy metal contamination on the shallot bulbs, among others, comes from the medium where the plants grow. Heavy metal content in the soil (pre-research) respectively: $\mathrm{Pb}$ (33.612), Cd (undetectable), and $\mathrm{Cu}$ (52.251) ppm. Meanwhile, the heavy metal content in manure added to the land consecutively: $\mathrm{Pb}(15,659), \mathrm{Cd}$ (undetectable), while $\mathrm{Cu}(35,118) \mathrm{ppm}$.
\end{abstract}

Keywords: Food-safety, shallots, heavy metals

\begin{abstract}
ABSTRAK
Tujuan penelitian ini adalah untuk mengetahui pengaruh faktor perlakuan dosis pupuk kandang terhadap hasil bawang merah dan pencemaran logam berat $\mathrm{Pb}, \mathrm{Cd}$, dan $\mathrm{Cu}$. Faktor penelitian meliputi penggunaan kotoran sapi yang terdiri dari 9 taraf dosis, yaitu: $0,15,20,25,30,35,40,45$ dan $50 \mathrm{~kg} / \mathrm{ha}$. Hasil penelitian menunjukkan bahwa peningkatan dosis pupuk kandang diikuti dengan peningkatan hasil umbi bawang merah. Hasil tertinggi umbi bawang merah $(3.897,76) \mathrm{kg} / \mathrm{ha}$ dicapai pada perlakuan dosis kotoran sapi $50 \mathrm{~kg} / \mathrm{ha}$, perlakuan berbeda nyata dengan hasil umbi bawang merah (3.634,73 kg/ha dengan dosis pupuk kandang). perlakuan pupuk kandang ternak $45 \mathrm{~kg} / \mathrm{ha}$. Sedangkan hasil bawang merah terendah $(1.875,86) \mathrm{kg} / \mathrm{ha}$ dicapai pada perlakuan $0 \mathrm{~kg} / \mathrm{ha}$ tanpa pupuk kandang. Pencemaran logam berat pada umbi bawang merah pada perlakuan dosis kotoran sapi $50 \mathrm{~kg} / \mathrm{ha}$ berturutturut: $\mathrm{Pb}$ (15.350) ppm, batas deteksi Cd (tidak terdeteksi) sebesar $0.01 \mathrm{ppm}$, dan $\mathrm{Cu}$ (4.255) ppm. Pencemaran logam berat pada umbi bawang merah antara lain berasal dari media tempat tumbuh tanaman. Kandungan logam berat dalam tanah (pra penelitian) berturut-turut: $\mathrm{Pb}(33,612), \mathrm{Cd}$ (tidak terdeteksi), dan $\mathrm{Cu}(52,251) \mathrm{ppm}$. Sedangkan kandungan logam berat dalam pupuk kandang yang ditambahkan ke tanah berturut-turut: $\mathrm{Pb}(15,659)$, $\mathrm{Cd}$ (tidak terdeteksi), sedangkan $\mathrm{Cu}(35,118) \mathrm{ppm}$.
\end{abstract}

Kata Kunci: Keamanan Pangan, Bawang Merah, Logam Berat

PENDAHULUAN
Keberhasilan pembangunan pertanian dan industri dapat menimbulkan dampak negatif terhadap lingkungan, terutama terhadap kualitas sumber daya lahan. Pencemaran logam berat pada lahan pertanian merupakan masalah 
JURNAL ILMIAH AGRINECA

ISSN : 2721-074X (Online) - 2301-6698 (Print)

Available on : http://ejournal.utp.ac.id/index.php/AFP/index

This is Under CC BY SA Licence

lingkungan pada umumnya, yang dapat mengurangi produktivitas tanaman dan keamanan pangan (Zheljazkov dkk., 2006). Sumber utama logam berat pada tanaman adalah media pertumbuhan, sebagai larutan hara dan tanah. Sejauh mana tanaman menyerap logam, tergantung pada logam berat yang terdapat dalam tanah dan sumber lain termasuk agrokimia (Ansari dkk., 2009). Akumulasi logam berat dalam tanah, risiko serapan oleh tanaman yang diikuti masuknya dalam rantai makanan, sekarang menjadi masalah keprihatinan yang besar (Lavado dkk., 2001).

Tanaman mudah menyerap logam berat dari tanah dan mengangkutnya ke tunas (jaringan meristem), sehingga masuk ke tubuh manusia melalui rantai makanan (Drazic dan Mihailovic, 2005). Menurut Priyadi, (2012), akumulasi $\mathrm{Pb}$ dan $\mathrm{Cd}$ pada biji kedelai hasil sistem budidaya tanpa pupuk anorganik masingmasing 0,48 $\pm 0,03 \mathrm{ppm}$ dan 0,1 $\pm 0,04 \mathrm{ppm}$. Akumulasi $\mathrm{Pb}$ dan $\mathrm{Cd}$ pada biji kedelai hasil sistem budidaya menggunakan pupuk anorganik masing-masing 0,63 $\pm 0,14$ ppm dan $0,05 \pm 0,02$ ppm.

\section{METODE PENELITIAN}

Bahan yang digunakan dalam penelitian ini terdiri dari bahan utama dan bahan kimia untuk analisis. Bahan utama berupa biji kedelai, asam sitrat sebagai chelating agent, $\mathrm{H} 2 \mathrm{SO} 4, \mathrm{HCl}$, $\mathrm{NaOH}, \mathrm{HNO} 3, \mathrm{HClO} 4$, dan larutan standar $\mathrm{Pb}$, $\mathrm{Cd}$ dan $\mathrm{Cu}$. Alat yang digunakan meliputi penangas listrik dan Atomic Absorption Spectrophotometer-flame (AAS Jena ContrAA 300).

Penelitian dalam rangka penerapan good agricultural practices ini dilaksanakan di Gagaksipat, Ngemplak - Boyolali. Penelitian disusun dalam rancangan acak kelompok lengkap faktor tunggal. Data hasil penelitian yang dikumpulkan secara statistik diuji dengan anava dan apabila terdapat perbedaan pada perlakuan dilanjutkan uji Duncan's Multiple Range Test dengan taraf signifikansi 5\%. Faktor perlakuan dalam penelitian ini dosis pupuk kandang sapi yang terdiri dari 9 taraf, yaitu: 0 , 15, 20, 25, 30, 35, 40, 45 dan 50 ton/ha.

Sampel uji dilakukan destruksi basah dengan prosedur kerja sebagai berikut: a) sebanyak 5 gram bahan dimasukkan ke dalam Erlenmeyer; b) ditambahkan $40 \mathrm{ml}$ asam sitrat perklorat $(2: 1)$; c) Erlenmeyer diletakkan di atas penangas listrik, suhunya diatur pada suhu rendah $\left(100^{\circ} \mathrm{C}\right)$; setelah larutan dalam Erlenmeyer mulai mendidih (asap merah akan hilang); d) pemanasan dilanjutkan sampai air dan asam nitrat hilang; e) setelah reaksi antara sampel dengan asam perklorat sempurna (dapat diidentifikasi dengan dengan hilangnya effervescent), digunakan pemanas yang tinggi $\left(170^{\circ} \mathrm{C}\right)$ sampai jernih dan timbul asap putih. dihindarkan pemanasan yang membuat sampel hingga mengering, karena akan terjadi letupan; f) Erlenmeyer diturunkan dari penangas listrik dan biarkan dingin; g) sampel yang telah didigesti dipindahkan ke dalam labu takar $25 \mathrm{ml}$ dan ditambahkan aquades sampai batas tanda dan h) baca larutan dengan AAS-flame yang telah dikalibrasi sebelumnya (Assocoation of Offical Analytical Chemist, Gonzales and Herrador, 2007).

\section{HASIL DAN PEMBAHASAN}

\section{Hasil umbi bawang merah}

Berdasarkan hasil penelitian pada tabel 1 dapat dinyatakan bahwa, hasil umbi bawang merah dipengaruhi oleh peningkatan dosis pupuk kandang. Penggunaan lahan secara terusmenerus untuk usahatani tanaman semusim mempercepat penurunan bahan organik tanah, yang laju penurunannya dipengaruhi oleh tekstur tanah (Bationo et al. 2006). Haynes dan Mokolobate (2001) menyatakan bahwa dekomposisi bahan organik tanah menghasilkan asam humat dan fulvat. Proses dekomposisi bahan organik menghasilkan $\mathrm{OH}^{-}$, sehingga akan menaikkan $\mathrm{pH}$ tanah. Peran penting bahan organik terhadap sifat fisiko-kimia tanah adalah peningkatkan kapasitas tukar kation tanah (Rahardjo 2000). Penggunaan pupuk organik meningkatkan hasil biji $58 \%$ dibanding 


\section{JURNAL ILMIAH AGRINECA \\ ISSN : 2721-074X (Online) - 2301-6698 (Print) \\ Available on : http://ejournal.utp.ac.id/index.php/AFP/index \\ This is Under CC BY SA Licence}

perlakuan pemupukan anorganik dengan dosis

dan Umar 2011).

22,5 $\mathrm{kg} \mathrm{N}, 67,5 \mathrm{~kg} \mathrm{P}_{2} \mathrm{O}_{5}, 30 \mathrm{~kg} \mathrm{~K}_{2} \mathrm{O}$ (Indrayani

Tabel 1. Hasil umbi bawang merah dalam kajian dosis pupuk kandang sapi

\begin{tabular}{cc}
\hline $\begin{array}{c}\text { Dosis pupuk kandang sapi } \\
(\mathbf{k g} / \mathbf{h a})\end{array}$ & $\begin{array}{c}\text { Hasil bawang merah } \\
(\mathbf{k g} / \mathbf{h a})\end{array}$ \\
\hline 10 & $1.875,86 \quad \mathrm{a}$ \\
15 & $2.189,20$ ab \\
20 & $2.423,79$ ab \\
25 & $2.668,16$ abc \\
30 & $2.797,73$ abcd \\
35 & $3.289,45$ bcd \\
40 & $3.341,72$ bcd \\
45 & $3.634,73$ cd \\
50 & $3.897,76 \quad$ d \\
\hline
\end{tabular}

Sumber: Analisis Data Primer, 2020

\section{Kadar cemaran logam berat pada media tanam dan pupuk kandang}

Berdasarkan hasil analisis menggunakan AAS (Atomic Absorption Spectrophotometer - flame) kadar cemaran logam berat pada tanah (media tanam) pra-tanam dan pupuk kandang sapi yang digunakan dalam penelitian disajikan pada (Tabel 2).

Tabel 2. Kadar $\mathrm{Pb}, \mathrm{Cd}$, dan $\mathrm{Cu}$ pada tanah (media tanam) pra-tanam dan pupuk kandang sapi

\begin{tabular}{ccc}
\hline Logam berat & \multicolumn{2}{c}{ Kadar logam berat (ppm) } \\
& Tanah (pra-tanam) & Pupuk kandang sapi \\
\hline $\mathrm{Pb}$ & $33,612 \pm 1,450$ & $15,659 \pm 2,701$ \\
$\mathrm{Cd}$ & nd & nd \\
$\mathrm{Cu}$ & $52,251 \pm 0,751$ & $35,118 \pm 0,982$ \\
\hline
\end{tabular}

Keterangan:

nd ---- tidak terdeteksi, batas deteksi (0,01 ppm)

Sejarah penggunaan lahan, merupakan lahan pertanian dengan pola tanam padi palawija (jagung) - palawija (kacang tanah), yang dikelola dengan sistem pertanian konvensional, yaitu menggunakan input pupuk anorganik (ZA, Urea, dan NPK (phonska), serta pestisida kimia sintetis. Penggunaan pupuk anorganik (ZA, phonska dan urea) pada budidaya padi dengan dosis secara berturutturut 300,300 dan $100 \mathrm{~kg} / \mathrm{ha}$ serta petroganik $500 \mathrm{~kg} / \mathrm{ha}$.

Menurut Charlena (2004) pupuk anorganik (golongan fosfat dan nitrat) mengandung logam berat $\mathrm{Pb}$ masing-masing $7-225 \mathrm{ppm}$ dan $2-27$ ppm, sedangkan kandungan $\mathrm{Cd}$ masing-masing 0,1 - $170 \mathrm{ppm}$ dan 0,05-8,5 ppm, sedangkan kandungan $\mathrm{Cu}$ pada pupuk anorganik golongan fosfat $1-300 \mathrm{ppm}$. Disamping itu pupuk kandang mengandung logam berat $\mathrm{Pb} 1,1-27$

ppm, Cd 0,1 - 0,8 ppm dan $\mathrm{Cu} 2-172$ ppm. Menurut Mousavi et al., (2010) pemupukan dengan pupuk anorganik $100 \mathrm{~kg} / \mathrm{ha}$ urea, 150 $\mathrm{kg} / \mathrm{ha}$ TSP, $100 \mathrm{~kg} / \mathrm{ha}$ potasium sulfat menyebabkan kadar logam berat dalam tanah $\mathrm{Pb}$ 33,57 ppm, sedangkan Cd 1,58 ppm.

\section{Kadar cemaran logam berat pada umbi bawang merah}

Berdasarkan hasil analisis menggunakan AAS (Atomic Absorption Spectrophotometer flame) kadar cemaran logam berat pada umbi bawang merah yang ditanam dengan berbagai taraf dosis pupuk kandang sapi disajikan pada (Tabel 3). 
JURNAL ILMIAH AGRINECA

ISSN : 2721-074X (Online) - 2301-6698 (Print)

Available on : http://ejournal.utp.ac.id/index.php/AFP/index

This is Under CC BY SA Licence

Tabel 3. Kadar cemaran logam berat pada umbi bawang merah yang ditanam dengan berbagai taraf dosis pupuk kandang

\begin{tabular}{cccc}
\hline $\begin{array}{c}\text { Dosis pupuk kandang } \\
\text { sapi (kg/ha) }\end{array}$ & \multicolumn{2}{c}{ Kadar logam berat pada umbi bawang merah (ppm) } \\
$\mathbf{~ P b}$ & $5.814 \pm 1,450$ & Cd & $\mathbf{C u}$ \\
\hline 10 & $8.828 \pm 0,466$ & nd & $2.819 \pm 0,268$ \\
15 & $7.588 \pm 0,599$ & nd & $3.642 \pm 0,260$ \\
20 & $9.117 \pm 0,381$ & nd & $3.468 \pm 0,740$ \\
25 & $10.176 \pm 1,405$ & nd & $3.817 \pm 0,273$ \\
30 & $11.371 \pm 1,521$ & nd & $3.707 \pm 0,740$ \\
35 & $12.763 \pm 0,599$ & nd & $3.741 \pm 0,740$ \\
40 & $12.977 \pm 1,409$ & nd & $3.311 \pm 0,257$ \\
45 & $15.350 \pm 0,470$ & nd & $3.955 \pm 0,740$ \\
50 & & & $4.255 \pm 0,335$ \\
\hline
\end{tabular}

Keterangan:

nd ---- tidak terdeteksi, batas deteksi (0,01 ppm)

Lahan penelitian merupakan persawahan (tanaman padi) yang dikelola secara konvensional, yaitu input pupuk anorganik ZA, phonska dan urea dengan dosis secara berturutturut 300, 300 dan $100 \mathrm{~kg} / \mathrm{ha}$ serta petroganik $500 \mathrm{~kg} / \mathrm{ha}$. Pupuk anorganik dan organik yang digunakan pada musim tanam sebelumnya menyebabkan residu logam berat di lahan. Logam berat tersebut diserap oleh akar tanaman dan terdistribusi pada jaringan tanaman yang ada di dalam tanah maupun yang berada di atas tanah. Berdasarkan hasil penelitian pada tabel 2 dapat dinyatakan bahwa, umbi bawang merah tercemar logam berat $\mathrm{Pb}$ maupun $\mathrm{Cu}$.

Menurut Mousavi et al., (2010), pupuk anorganik dengan dosis $100 \mathrm{~kg} / \mathrm{ha}$ urea, $150 \mathrm{~kg}$ ha-1 TSP, dan $100 \mathrm{~kg} / \mathrm{ha}$ potasium sulfat, menyebabkan kadar logam berat $\mathrm{Pb}$ pada biji padi 64,44 ppm dan Cd 11,61 ppm. Pupuk organik vermikompos menyebabkan kadar logam berat $\mathrm{Pb}$ pada biji padi menjadi 59,26 ppm dan Cd 11,18 ppm.

\section{KESIMPULAN}

Berdasarkan hasil penelitian dinyatakan bahwa, hasil umbi bawang merah dipengaruhi oleh dosis pupuk kandang, yaitu meningkat seiring dengan peningkatan dosis pupuk kandang. Kadar logam berat pada umbi bawang merah berada di atas batas maksimum cemaran logam berat dalam pangan yang ditetapkan dalam SNI 7389:2009. Dalam rangka meningkatkan keamanan pangan dari aspek cemaran logam berat, dan mengacu pada hasil penelitian ini, maka perlunya penelitian lanjutan tentang: penggunaan organic chelating agent.

\section{DAFTAR PUSTAKA}

Anonim, 2013. Sistem pertanian Organik. Peraturan Menteri Pertanian No. 64/Permentan/OT. 140/5/2013.

Ansari, R., Kazi, T. G., Jamali, M. K., Arain, M. B., Wagan, M. D., Jalbani, N., Afridi, H. I. and Shah, A. Q. 2009. Variation in accumulation of heavy metals in different verities of sunflower seed oil with the aid of multivariate technique. Food Chemistry 115: 318-323.

Balia, R.L., Harlia, E., Denny dan Suryanto, 2007. Keamanan Pangan Hasil Ternak Ditinjau Dari Cemaran Logam Berat. Fakultas Peternakan Universitas Padjadjaran. blogs.unpad.ac.id.

Bationo, A., J. Kihara, B. Vanlauwe, B. Waswa, and J. Kimetu. 2006. Soil organic carbon dynamics, functions and management in West African agro-ecosystems. Agricultural Systems Journal.

Lavado, R. S., Porcelli, C. A and Alvarez, R. 2001. Nutrient and heavy metal concentration and distribution in corn, soybean and wheat as affected by different tillage systems in the argentine pampas. Soil and Tillage Research $62: 55-60$.

Mendoza-Cózatl, D. G., Jobe, T. O., Hauser, F. and Schroeder, J. I. 2011. Long-distance transport, 
JURNAL ILMIAH AGRINECA

ISSN : 2721-074X (Online) - 2301-6698 (Print)

Available on : http://ejournal.utp.ac.id/index.php/AFP/index

This is Under CC BY SA Licence

vacuolar sequestration, tolerance, and transcriptional responses induced by cadmium and arsenic. Plant Biology 14: 554-562.

Muzaiyanah, S., dan Subandi, 2016. Peranan Bahan Organik dalam Peningkatan Produksi Kedelai dan Ubi Kayu pada Lahan Kering Masam. Balai Penelitian Kacang-kacangan dan Umbiumbian.

Mousavi, S. M., Bahmanyar, M. A. and Pirdashti, H. 2010. Lead and cadmium availability and uptake by rice plant in response to different biosolids and inorganic fertilizers. American Journal of Agricultural and Biological Sciences5 (1): 25-31.

Priyadi, S., Darmaji, P., Santoso, U., dan Hastuti, P., 2012. Profil Plumbum $(\mathrm{Pb})$ dan Cadmium (Cd) sebagai Kontaminan Dampak Penggunaan Agrokimia serta Remediasi Biji Kedelai Menggunakan Swelling Agent pada Khelasi dengan Asam Sitrat. Jurnal Natur Indonesia 15 (1), Lembaga Penelitian Universitas Riau.

2013. Khelasi Plumbum $(\mathrm{Pb})$ dan Cadmium (Cd) Menggunakan Asam Sitrat pada Biji Kedelai. Jurnal Agritech 33 (4), Fakultas Teknologi Pertanian Universitas Gadjah Mada.

2014. Distribusi Plumbum, Cadmium Pada Biji Kedelai dan Deprotonasi Gugus Fungsional Karboksil Asam Sitrat Dalam Khelasi. Jurnal Agritech 34 (4), Fakultas Teknologi Pertanian Universitas Gadjah Mada.

2016. Kajian Penumbuhan Good Agricultural Practices Hortikultura dengan
Inovasi Teknologi Pertanian Berkelanjutan Menuju Pemenuhan Mutu dari Aspek Keamanan Pangan" (Laporan Penelitian Unggulan Perguruan Tinggi), Agroteknologi Fakultas Pertanian Universitas Tunas pembangunan.

2018. Perbaikan Kualitas Biji Kedelai yang Tercemar $\mathrm{Pb}$ dan $\mathrm{Cd}$ Formasi pada Komplek Phytochelatin dan Mekanisme Khelasi pada Biji. Jurnal Agritech 18 (1) Fakultas Teknologi Pertanian Universitas Gadjah Mada.

2019. Identifikasi Logam Berat dalam Biji Jagung Manis dan Kedelai pada Transisi Sistem Pertanian Organik. Jurnal Agritech 38 (4) Fakultas Teknologi Pertanian Universitas Gadjah Mada

Setiawan, B., 2008. Peran Asam Humus Sebagai Pendesorpsi Ion Logam/Radionuklida. Pusat Teknologi Limbah Radioaktif-Batan Kawasan Puspitek Serpong, Tangerang 15310, Banten. Seminar Nasional IV SDM Teknologi Nuklir Yogyakarta.

Ullah, S. 2007. Chemically enhanced phytoextraction of lead from contaminated soil. Institute of Soil and Environment Sciences University of Agriculture, Faisalabad Pakistan. www.researchgate.net [diunduh 18 Februari 2012].

Zheljazkov, V. D., Jeliazkova, E. A., Kovacheva, N. and Dzhurmanski, A. 2008. Metal uptake by medicinal plant species grown in soils contaminated by a smelter. Environmental and Experimental Botany 64: 207-216. 